\title{
Carriage of ESBL-producing Enterobacterales in wastewater treatment plant workers and surrounding residents - the AWARE Study
}

\author{
Daloha Rodríguez-Molina ${ }^{1,2,3}$ (1) $\cdot$ Fanny Berglund ${ }^{4,5}$ (1) Hetty Blaak ${ }^{6}$ (D) Carl-Fredrik Flach $^{4,5} \cdot$ Merel Kemper $^{6}$.

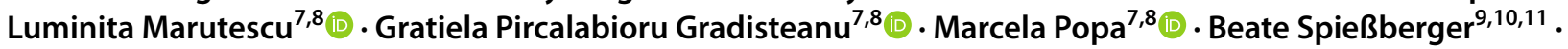

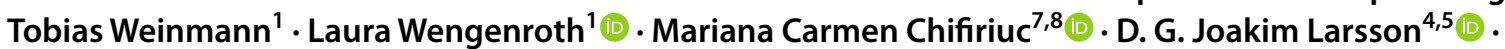

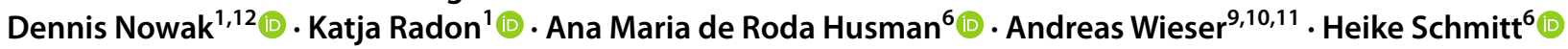

Received: 22 July 2021 / Accepted: 29 November 2021

(C) The Author(s) 2021

\begin{abstract}
To investigate whether wastewater treatment plant (WWTP) workers and residents living in close proximity to a WWTP have elevated carriage rates of ESBL-producing Enterobacterales, as compared to the general population. From 2018 to 2020, we carried out a cross-sectional study in Germany, the Netherlands, and Romania among WWTP workers $(\mathrm{N}=344)$, nearby residents (living $\leq 300 \mathrm{~m}$ away from WWTPs; $\mathrm{N}=431$ ) and distant residents (living $\geq 1000 \mathrm{~m}$ away $=$ reference group; $\mathrm{N}=1165$ ). We collected information on potential confounders via questionnaire. Culture of participants' stool samples was performed with ChromID®-ESBL agar plates and species identification with MALDI-TOF-MS. We used logistic regression to estimate the odds ratio (OR) for carrying ESBL-producing E. coli (ESBL-EC). Sensitivity analyses included stratification by country and interaction models using country as secondary exposure. Prevalence of ESBL-EC was $11 \%$ (workers), 29\% (nearby residents), and 7\% (distant residents), and higher in Romania (28\%) than in Germany (7\%) and the Netherlands (6\%). Models stratified by country showed that within the Romanian population, WWTP workers are about twice as likely (aOR $=2.34,95 \% \mathrm{CI}: 1.22-4.50)$ and nearby residents about three times as likely $(\mathrm{aOR}=3.17$, 95\% CI: 1.80-5.59) to be ESBL-EC carriers, when compared with distant residents. In stratified analyses by country, we found an increased risk for carriage of ESBL-EC in Romanian workers and nearby residents. This effect was higher for nearby residents than for workers, which suggests that, for nearby residents, factors other than the local WWTP could contribute to the increased carriage.
\end{abstract}

Keywords Antimicrobial resistance - Antibiotic resistance - ESBL-producing E. coli . Wastewater treatment plants . Environmental exposure

\section{Introduction}

Antibiotic resistance (AR) is currently one of the most important threats to public health and clinical medicine. In some regions, current AR rates are alarmingly high, with $58.4 \%$ of Escherichia coli (E. coli) isolates reported in 2018 to the European Antimicrobial Resistance Surveillance Network being resistant to at least one antibiotic group under surveillance (i.e. aminopenicillins, fluoroquinolones, third-generation cephalosporins, aminoglycosides and

Daloha Rodríguez-Molina

daloha.rodriguez_molina@med.uni-muenchen.de

Extended author information available on the last page of the article carbapenems) [1]. This is partly due to the use, overuse, and misuse of antibiotics by healthcare professionals and patients, but also in animal husbandry and agriculture [2-6]. Antibiotic resistant bacteria (ARB) can be introduced into the environment by different routes [7], including wastewater from the general human population [8-15]. These residual waters arrive and are collected at municipal wastewater treatment plants (WWTPs). Enteric ARB such as $E$. coli, as well as Klebsiella spp., Enterobacter spp., Serratia spp., and Citrobacter spp. (KESC) have been found in water [16-22] and air [23-25] samples from WWTPs. Moreover, the WWTPs effluents can discharge ARB into nearby water bodies because eliminating ARB is not part of the current wastewater treatment processes, which focus instead on reducing nutrient loads and pathogens to the receiving 
surface water. While some studies have reported either no changes in relative abundances of ARB [26] or a decrease in absolute and relative abundance of ARGs [27-29], other studies have reported an increased relative prevalence of ARB after wastewater treatment processes, in comparison to the untreated wastewater entering the plant $[16,17,22$, 30-38]. These aspects make WWTPs potential transmission hubs for the spread of ARB into the environment [39].

It has been proposed that ARB could be transmitted to humans by the air or wastewater at the WWTPs through different exposure routes including ingestion of droplets, hand-to-mouth contact, or inhalation of aerosols [21-24]. Further, an increased prevalence of gastrointestinal and respiratory diseases [40], as well as high levels of antibodies against bacteria, viruses, and parasites in WWTP workers, suggests an increased exposure to these pathogens [41-43]. Under this scenario, and extending this idea to AR, WWTP workers would be at a high risk of exposure to ARB. Furthermore, and considering that extended-spectrum betalactamase (ESBL)-producing E. coli (ESBL-EC) can be found up to $150 \mathrm{~m}$ both up- and downwind away from animal farms [44], nearby residents living in close proximity to WWTPs could also be highly exposed to these ARB. However, to our knowledge, no large-scale study has yet been carried out in humans potentially at risk of carriage of antibiotic resistant Enterobacterales working at or living close to WWTPs. Such studies are critical to aid our current understanding of the exposure status of humans working at or living around WWTPs, and to devise preventive strategies and interventions to reduce this potential exposure.

Therefore, in the present study, we aimed at investigating whether WWTP workers and residents living in close proximity to a WWTP have elevated carriage rates of ESBL-producing Enterobacterales, as compared to the general population. Our hypothesis is that the risk of carrying ESBL-producing Enterobacterales increases with proximity to the WWTP.

\section{Materials and methods}

\section{Study design and population}

The project "Antibiotic Resistance in Wastewater: Transmission Risks for Employees and Residents around Wastewater Treatment Plants (AWARE)" is a cross-sectional study, with data collection carried out from September 2018 to March 2020 in three European countries with different background prevalences for AR: Germany, the Netherlands, and Romania. A thorough description of the study methodology can be found elsewhere [45]. Briefly, our target population consisted of two exposed groups working at or living in close proximity to wastewater treatment plants (WWTP workers and nearby residents) and one unexposed population of distant residents. Nearby residents were defined as living within a 300-m radius from a WWTP, while distant residents were defined as living more than $1000 \mathrm{~m}$ away from a WWTP. Data on nearby residents was only collected in Germany and Romania, while data on WWTP workers and distant residents was collected in all three countries. The process of recruiting participants per country is described as follows.

\section{Germany}

We generated a sampling frame of WWTPs and ranked them in descending order based on number of employed workers and of estimated nearby residents in their vicinity to maximize the chances of achieving the minimum sample size for these two exposed groups. Out of 18 eligible WWTPs with the largest number of employed workers and nearby residents, eight were interested in participating and were thus invited into the study. Of these eight plants, six were willing to participate, of which one had too few workers and was thus not eligible, one could not participate anymore because of the situation regarding COVID-19 in early 2020, and one was selected as a pilot phase plant because it had a lower number of workers and nearby residents (Fig. 1). The remaining three plants were enrolled in full participation.

After a pilot phase examining the feasibility of the study methods, a total of 137 workers employed at three WWTPs in Southern Germany were invited to participate in our study (response 22\%). For nearby and distant residents of each of these three WWTPs, postal addresses were obtained from the local civil registries whenever possible, and all individuals living at each household were invited to participate in our study via postal service. In study locations where this was not possible, we generated a sampling frame of addresses within the specified distances to the WWTP for nearby and distant residents using Google Maps ${ }^{\mathrm{TM}}$, and went door-todoor delivering invitation letters to mailboxes. In addition to the invitation letter, two reminders were sent to non-responders. In parallel, local newspapers published an article about the project on the same week that the participants received the invitation letter. We also carried out a recruitment campaign via Facebook, targeting potential participants within the desired age range and located at the study sites. All participants who successfully completed the study were eligible for a raffle of shopping vouchers with a total value of 1500 EUR. In total, we invited 1453 nearby residents within the eligible age range (response 6.95\%) and 3153 distant residents (response 11\%).

\section{The Netherlands}

In the Netherlands, WWTPs are managed by regional water authorities called waterboards. Our unit of recruitment for 


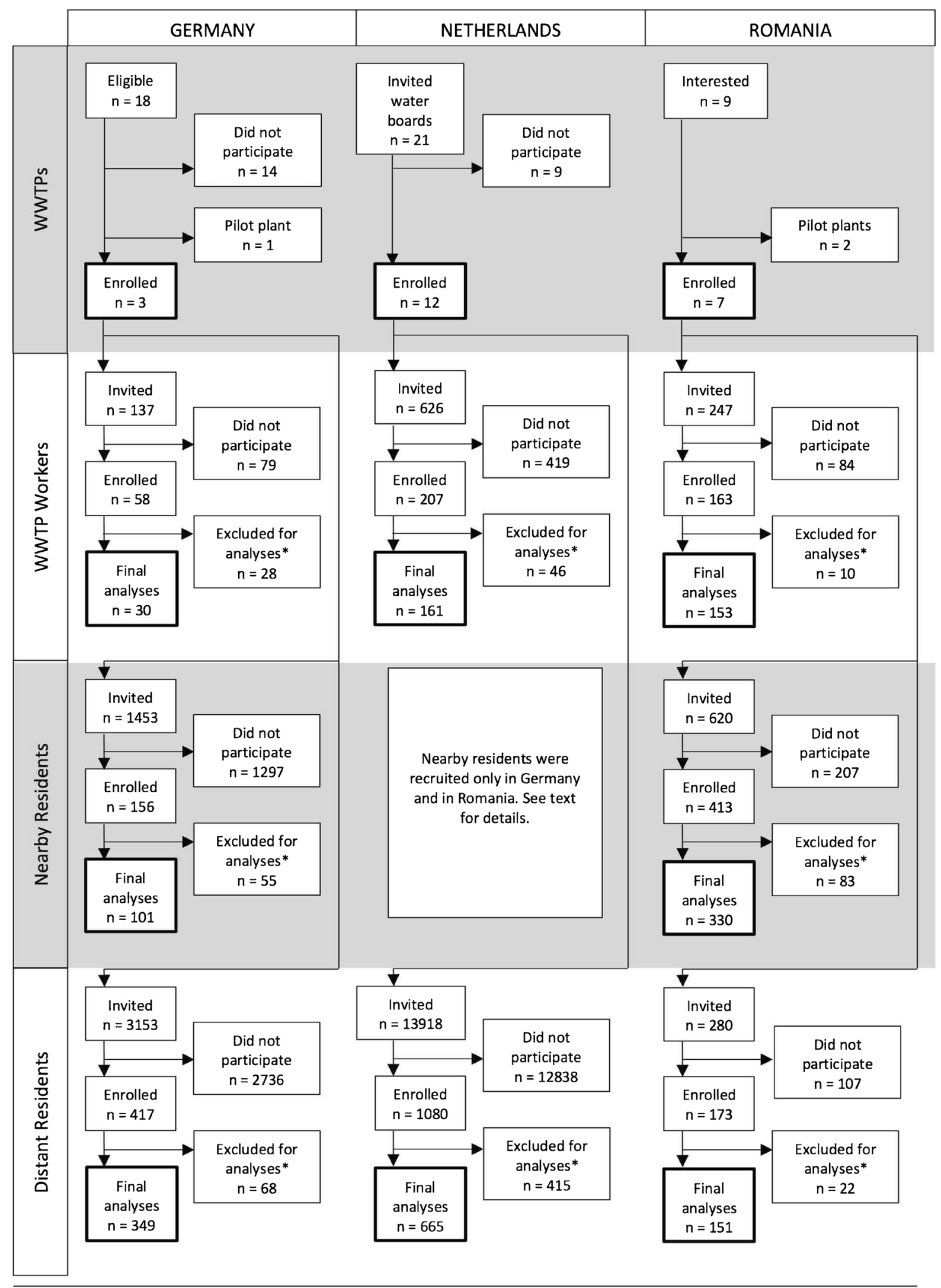

Fig. 1 Flow diagram of the recruitment process, AWARE Study, 2021 
the Netherlands was therefore the waterboard and not the WWTP. Of a total of 21 waterboards across the whole country, 12 were interested in participating in the study. Overall, 626 WWTP workers were invited to participate using a combination of WWTP visits for presenting the study plus invitations by e-mail in ten out of these twelve WWTPs, and using only e-mail invitations in the remaining two plants (response 26\%). We did not carry out data collection for residents living in close proximity to WWTPs in the Netherlands. For distant residents, general practitioners (GP) practices located 2 to $5 \mathrm{~km}$ away from the selected WWTPs were identified and these GPs were invited to cooperate with us as their practices served as a collection and preservation point for stool samples. Using ArcGis [46], we then identified all postal addresses within a 500-m radius from the cooperating GP practices, and then, using the Dutch Personal Records Database, we randomly retrieved the contacting information of potential participants living in 300-500 addresses surrounding each GP practice. A total number of 13,918 individuals living at these addresses received an invitation letter per postal service, of which 1080 responded to the invitation (recruitment response 7.8\%). Of these 13,918 invited people, 10,448 individuals were between the age of 16 and 67 years old and thus eligible by age (response among eligible individuals $6.4 \%$ ). All participants completing the study received a gift card worth 20 EUR.

\section{Romania}

WWTP operators were recruited through a formal letter containing information about the project and an invitation to join the study. Nine plants were invited, of which two were pilot plants, and all of them were ultimately enrolled in the study. WWTP workers from participating plants were contacted by their respective operators and invited to participate. A total number of 247 workers were reached (response $62 \%)$. Nearby and distant residents were invited to participate using the door-to-door approach. Further, potential participants in public places like streets, parks, and markets in the vicinity of WWTPs were also addressed orally and invited to participate, given that they were eligible. In total, we contacted 620 nearby and 280 distant residents within the eligible age range (response 53\% and 54\%).

\section{Data collection}

\section{Exposure of interest}

We consider ingestion of droplets, hand-to-mouth contact, or inhalation of aerosols the main exposure routes for WWTP workers. Nearby residents would be exposed through inhalation of aerosols. Therefore, we used the variable participation group (WWTP worker, nearby resident, distant resident) as a proxy variable for the exposure. We defined WWTP workers as the highest exposed group followed by nearby residents as the second most-exposed group, while distant residents served as an unexposed comparison group. Nearby residents were defined as persons living fewer than $300 \mathrm{~m}$ away from the WWTP. Distant residents were defined as persons living further than $1000 \mathrm{~m}$ away from any WWTPs.

\section{Outcome of interest}

The main outcome of interest was the presence of ESBLEC in stool samples, reported binarily (positive/negative). A secondary outcome of interest was the presence of bacteria from the Klebsiella, Enterobacter, Citrobacter, and Serratia (KESC) group in stool samples, also reported binarily (positive/negative). In Germany and Romania, only participants who successfully filled in the study questionnaire were sent a stool sample kit. In the Netherlands, enrolled participants were required to hand in a stool sample before receiving a link to fill in the online questionnaire. Nearby and distant residents received a stool sample collection kit by postal service, whereas workers received it at their workplace. Each participant was asked to record the date and time of stool sample collection, maintain the sample refrigerated (temperature ranging from 2 to $8{ }^{\circ} \mathrm{C}$ ), and bring it to the closest collection point (WWTPs or main train station in Germany, WWTPs or GP offices in the Netherlands, home visits in Romania). Samples were transported to the laboratory in cooling boxes within $24 \mathrm{~h}$ after sampling, where they were stored at $4{ }^{\circ} \mathrm{C}$, and processed within $24-48 \mathrm{~h}$ after sampling.

At the local laboratories in Germany, the Netherlands and Romania, all the stool samples were inoculated directly onto the following culture media: ChromID® ESBL (for ESBLEC), TBX (in the Netherlands and Romania) or MacConkey (in Germany) (for E. coli), and incubated at $36{ }^{\circ} \mathrm{C} \pm 1{ }^{\circ} \mathrm{C}$ for 24-48 h. In case of positive results, 2 separate isolates belonging to the ESBL-EC phenotype were collected from the ChromID ${ }^{\circledR}$ ESBL plate, screened for antibiotic resistance and identified by MALDI-TOF MS (Matrix Assisted Laser Desorption Ionization-Time of Flight Mass Spectrometry). Participants with a negative stool culture on TBX/ MacConkey were excluded from further analyses.

\section{Confounding variables}

Information on confounding variables was obtained from eligible individuals through an online questionnaire exploring sociodemographic characteristics, work history including contact with animals during farming or slaughterhouse activities, contact with patients or human tissues at work, international travels, use of antibiotics, hospital visits, and 
health condition (personal history of surgery, hospitalizations, chronic diseases, antibiotic and antacid intake, diarrhea, respiratory health, and self-reported health status), all in the past 12 months [45].

Educational level was asked using the educational structure of each country and then dichotomized using the International Standard Classification of Education (ISCED) [47-49] into low (0-2 ISCED points, i.e. pre-primary education to lower secondary education) and high (more than 2 ISCED points, i.e. upper secondary education to Doctoral or equivalent).

Work with patients or human tissues was constructed by merging the information of two separate survey questions: "In your current job, how often have you typically had direct interaction or contact with patients within in the last 12 months?" and "How often have you worked with human tissue, blood, body fluids (urine, feces, vomit, sputum, saliva) or primary cell lines within the last 12 months?" Each question could be answered with a frequency scale (never, rarely, sometimes, often, always). If the participant had answered rarely, sometimes, often or always in either of the two questions, a "yes" was assigned. Else, a "no" was assigned. Use of antibiotics was assessed with the question "Have you taken an antibiotic within the last 12 months?" to which possible answers were "Yes," "No," and "Do not know." Participants answering "Do not know" were assigned into the "No" category.

When asked about international travel, participants were asked to provide information about the region where they had been in the past year: Europe, Asia, North Africa, SubSaharan Africa, North America, Central America and Mexico, South America, and Australia and Oceania. For each of these regions, participants could state the frequency of travel within the last year: never, once, 2 to 3 times, more than 3 times, I don't know. Additionally, if the participant reported travels to Europe, they were asked about travels to specific European countries with a high background prevalence of ESBL-EC: Italy, Slovenia, Bulgaria, and Greece (yes/no). Travels to high-risk areas for ESBL was defined as reporting travels to at least one of the following areas or countries within the past year: Asia, North Africa, Sub-Saharan Africa, Central America and Mexico, South America, Italy, Slovenia, Bulgaria, and Greece.

\section{Statistical analyses}

To present summary statistics for the descriptive characteristics of the study population, numerical variables (i.e. age) were assessed visually for normality using histograms and are presented as mean \pm standard deviation if normally distributed or as median \pm inter-quartile range if non-normally distributed. Categorical variables are presented using absolute and relative frequencies. Either chi-square of Fisher's exact test was used for bivariate hypothesis testing of categorical variables, depending on cell counts.

We assume that the missing values in the outcome of interest are missing at random because it is highly unlikely that participants would know their personal status of ESBL$\mathrm{EC}$ in stools beforehand. We therefore proceeded to simulate missing values for this outcome and other variables of interest where the missingness mechanism was at random or completely at random by using multiple imputation with chained equations [50]. With twenty iterations per dataset, we generated a total of ten imputed datasets, from which we estimated regression models whose estimates were then pooled and reported. Because of the differences in participation response across countries, we weighted our study population using inverse probability of sampling weights [51]. Weights were defined as the inverse of the participation response per country and per participation group.

The direct causal effect of participation group (WWTP worker, nearby resident, distant resident) as a proxy for exposure routes (ingestion of droplets, hand-to-mouth contact, or inhalation of aerosols) in and around the local WWTP on the presence of ESBL-EC in participants' stool samples (no/yes) was estimated using logistic regression models. We present unweighted crude and adjusted estimates, weighted crude and adjusted estimates, and their corresponding 95\% confidence intervals in graphical form. Sensitivity analyses included models stratified by country, an interaction model with country as a secondary exposure, and models stratified by participation group.

Variable selection for the models was done using a combination of experts' opinion from within the AWARE consortium, evidence in the current literature, and the use of Directed Acyclic Graphs (DAGs) [52, 53] (Fig. 2). All analyses were done in $\mathrm{R}$ version 3.5.0 and up [54] using the following R packages: epiR [55], mice [56], mitml [57], mitools [58], and survey [59, 60].

\section{Results}

\section{Descriptive characteristics of the study population}

A total of 1940 participants across the three countries were eligible for analyses, with $25 \%$ of participants from Germany $(n=480), 43 \%$ from the Netherlands $(n=826)$, and $33 \%$ from Romania $(n=634$, Table 1$)$. The majority of the population was middle-aged (median age 49 years, IQR $36-58)$, female (52\%), and highly educated (64\%). Across the three countries, WWTP workers were mostly men and the majority reported contact with human tissues, which we attribute to the presence of human feces in wastewater.

In Germany, approximately two-thirds of the WWTP workers reported working with human tissues $(68 \%)$ in 


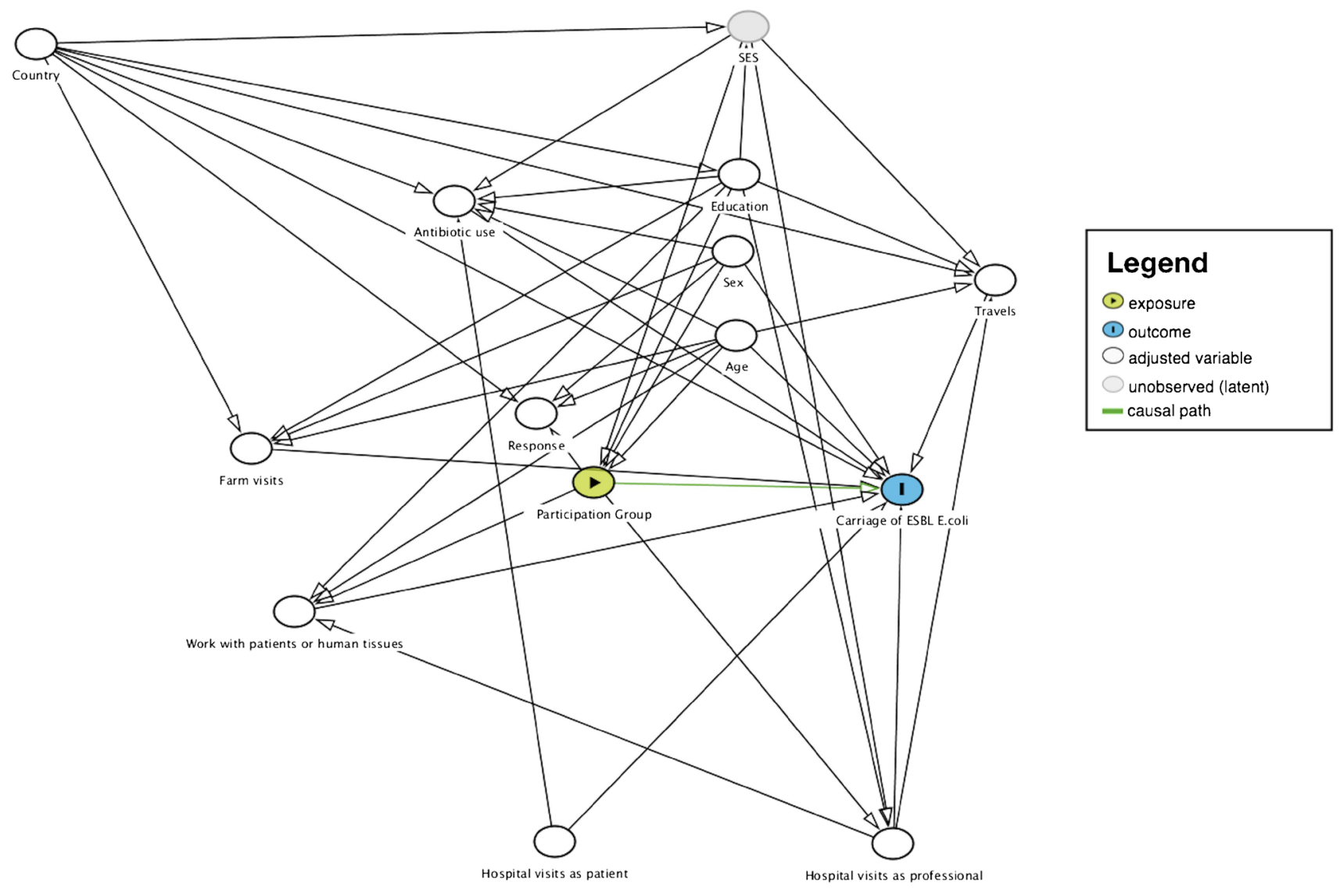

Fig. 2 Directed Acyclic Graph (DAG) for the direct effect of participation group (wastewater treatment plant-WWTP-worker, nearby resident, distant resident) as a proxy for exposure routes (ingestion

contrast to nearby and distant residents, where approximately a third of each group reported this type of contact at work (32\% and 35\%, p 0.0015). Distant residents from Germany were more highly educated than nearby residents, and these in turn more than WWTP workers $(72 \%$, $47 \%$, and $30 \%, \mathrm{p}<0.001$ ).

In the Netherlands, fewer WWTP workers reported using antibiotics in the past year in comparison to the distant residents $(11 \%$ vs. $20 \%, \mathrm{p}=0.01)$ and visiting hospitals as a patient $(1.2 \%$ vs. $6.0 \%, \mathrm{p}=0.02)$. More WWTP workers reported visiting farms than distant residents $(16 \%$ vs. $8.2 \%, \mathrm{p}=0.005)$.

In Romania, workers were, on average, older (median age among workers $49[41,53]$ vs. median age among distant residents $40[33,50]$ in distant residents) and better educated (97\% vs. 91) than distant residents. Also, in comparison to distant residents, nearby residents had a lower level of education (65\% vs. $91 \%$ ) and traveled less to high risk areas for AR (10\% vs. $33 \%)$. of droplets, hand-to-mouth contact, or inhalation of aerosols) in and around the local WWTP on the presence of ESBL-producing E. coli in stool samples, AWARE Study, 2021

\section{Carrier status for ESBL-producing Enterobacterales}

The overall prevalence of ESBL-EC across the three countries was $13 \%$, with the highest prevalence observed in the Romanian population (28\%). The prevalence of ESBLproducing bacteria of the KESC group across countries was $3.8 \%$, with the highest value observed also in Romania $(10 \%)$.

In Germany, ESBL-EC were not detected in stools of any of the workers $(n=30)$, but among $8.4 \%$ of distant residents and $5.7 \%$ of nearby residents. In the Netherlands, carriage of ESBL-EC was similar in WWTP workers (4.4\%) and distant residents $(6.0 \%)(\mathrm{p}=0.53)$. In Romania, the prevalence of ESBL-EC was $23 \%$ among workers, $36 \%$ among nearby residents, and $12 \%$ among distant residents $(\mathrm{p}<0.001)$.

Because the prevalence for KESC bacteria was relatively low and thus limiting the statistical power of our inferential analyses, we decided to focus only on the primary outcome: ESBL-EC. The effect of participation 


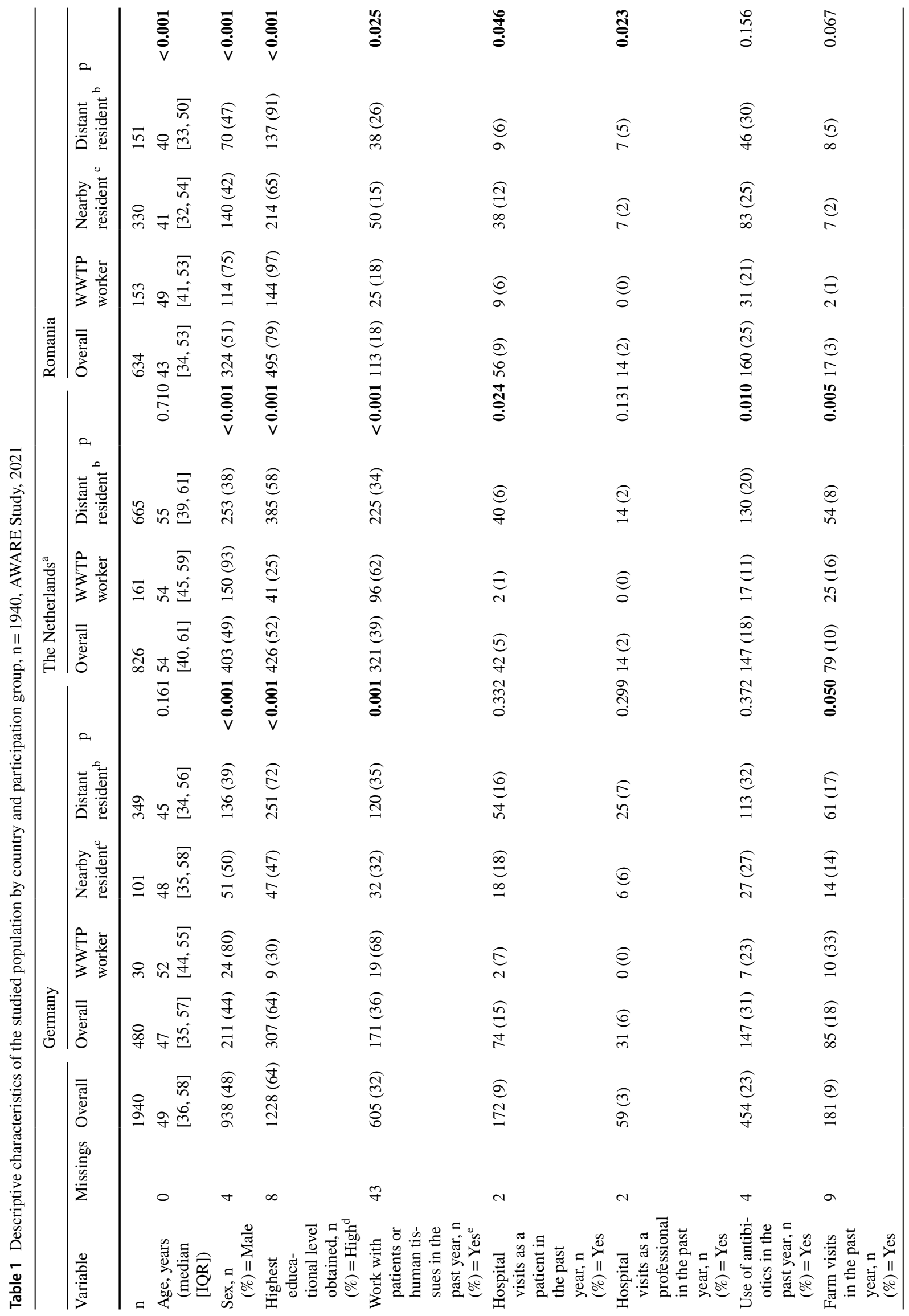




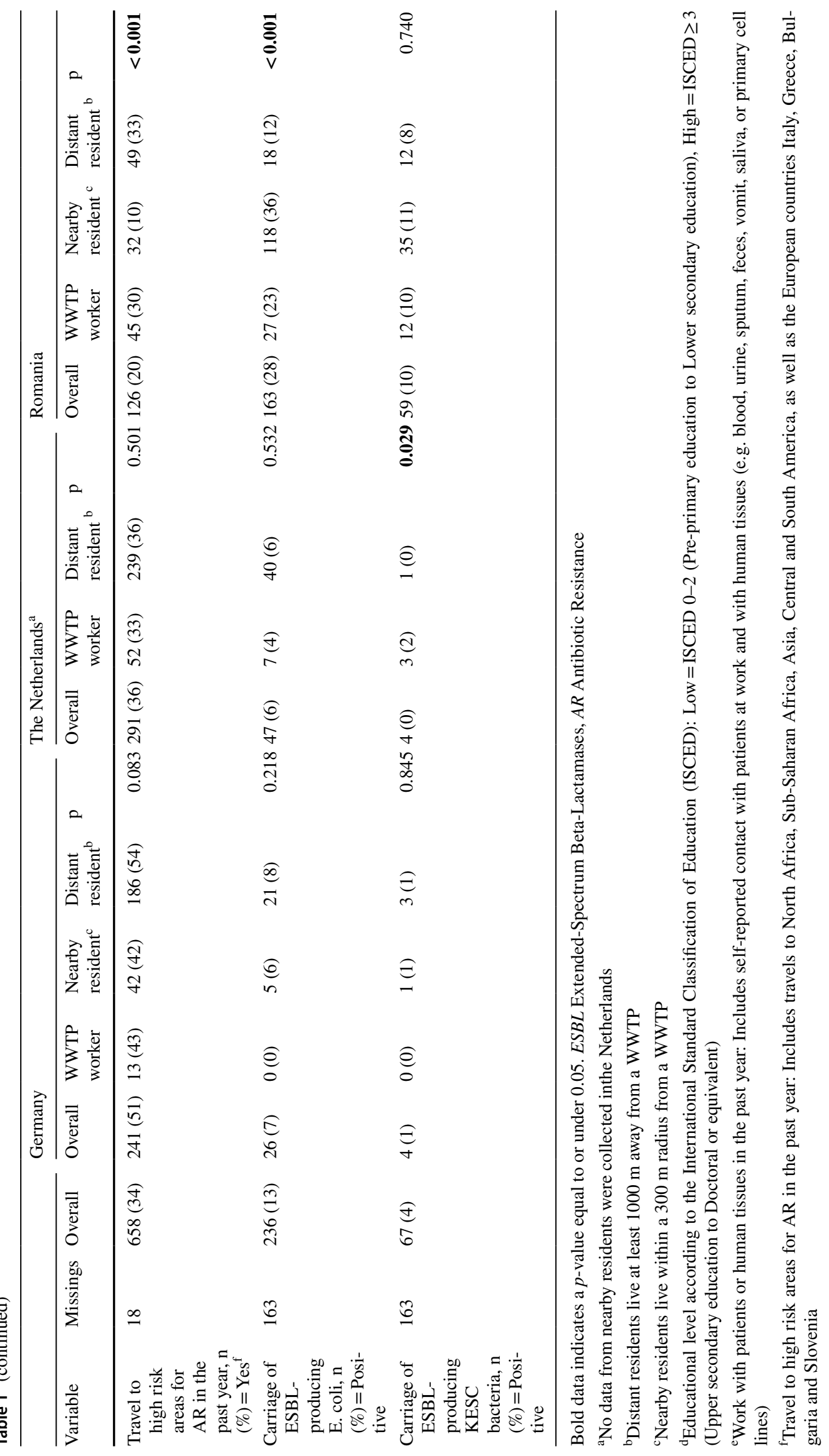


group (WWTP worker, nearby or distant resident) on the carriage of ESBL-EC varied by country (Online Resource Table 1). Overall, the proportion of WWTP workers and nearby residents with a positive stool sample for ESBLEC was higher than that of distant residents (11\% and 29\% vs. $7.5 \%, \mathrm{p}<0.001)$. This result was driven by the Romanian population $(23 \%$ and $36 \%$ vs. $12 \%, \mathrm{p}<0.001)$, while there were no statistically significant differences between participation groups in the proportions of positive ESBLEC carriers either in Germany $(0.0 \%$ and $5.7 \%$ vs. $8.4 \%$, $\mathrm{p}=0.22)$ or in the Netherlands $(4.4 \%$ vs. $6.0 \%, \mathrm{p}=0.53)$.

\section{Statistical models}

Across the three countries, the unweighted crude odds ratio for the carriage of ESBL-EC among WWTP workers was 1.71 (95\% CI: 1.12-2.61). Among nearby residents, it was 4.95 (95\% confidence interval, CI: 3.63-6.73), compared to the unexposed group (Fig. 3). These unweighted estimates changed to 1.17 (95\% CI: 0.74-1.86) for WWTP workers and 2.24 (95\% CI: 1.50-3.37) for nearby residents upon adjustment for age, sex, education, country, travels to high risk areas for AR, working with human tissues, antibiotic use, farm visits, hospital visits as patients, and hospital visits as a professional. After applying inverse probability of sampling weights for the response in each country and in each participation group, crude estimates changed to 1.28 (95\% CI: 0.82-2.00) among workers and to 2.46 (95\% CI: 1.65-3.69) among nearby residents, while the adjusted estimates changed to 0.76 (95\% CI: $0.44-1.29$ ) and 1.47 (95\% CI: 0.83-2.59), respectively.

Although we could not estimate an effect of exposure within the German and the Dutch subpopulations (Table 2), models stratified by country showed that, within the Romanian population, WWTP workers were about twice as likely (adjusted $\mathrm{OR}, \mathrm{aOR}=2.34,95 \% \mathrm{CI}$ : $1.22-4.50)$ and nearby residents about three times as likely $(\mathrm{aOR}=3.17,95 \% \mathrm{CI}: 1.80-5.59)$ to be ESBL-EC carriers, when compared with distant residents.

Additionally, and according to our weighted and adjusted model, participants who reported traveling to high risk areas for AR in the past 12 months were almost twice as likely to have a positive result for ESBL-EC in stool samples, as compared to participants who did not travel to these high-risk areas (aOR 2.06, 95\% CI: 1.33-3.19). None of the other covariates showed a statistically significant effect (see Online Resource Table 2 and Online Resource Fig. 1). The magnitude and direction of these estimates, as well as their confidence intervals, were fairly conserved in the stratified models by participation group (see Online Resource Fig. 2).

\section{Missing values}

The highest proportion of missing values was found in the carriage of ESBL-EC $(n=163,8.4 \%)$, driven mostly by the German population $(n=114,24 \%$, Table 1). A comparison of crude and adjusted odds ratios (OR) along with $95 \%$ CI for logistic regression models with complete case analysis and with the imputed dataset showed that the direction of effect did not change after imputation (Online Resource Table 3).

\section{Discussion}

Across the three countries, we found no evidence of an increased risk for carriage of ESBL-EC neither in WWTP workers nor in residents living in close proximity to these WWTPs, as compared to the general population. We did find, however, evidence of increased odds for carriage of ESBL-EC in WWTP workers and in nearby residents in the Romanian population. Contrary to what we initially hypothesized, the effect for nearby residents was higher than the effect for WWTP workers in Romania.

An increased background prevalence of ESBL-EC in Romania, supported by our data, could be a risk factor for ESBL-EC carriage that sets the Romanian study population apart from the German and the Dutch. Additionally, travel to high-risk areas for AR has been identified as a risk factor for the carriage of ESBL-producing Enterobacterales because of the increased background prevalence of AR in some travel destinations [61-65]. Our data show that participants travel differently to high-risk areas for AR depending on their original country of residence. In Germany, our data collection took place in the south of the country where residents tend to choose Italy or Slovenia for their vacations because of the close geographical proximity, resulting in approximately half of the German participants reporting travels to high-risk areas for AR (Table 1).

Finding a higher ESBL-EC estimate for nearby residents than for WWTP workers in Romania, even after adjustment for other potential confounders and sources of exposure, suggests that the main source of exposure for nearby residents might not be the local WWTP. Potential sources of exposure for which we did not collect data and that might uniquely affect nearby residents in Romania but not WWTP workers are mentioned as follows. Risk factors for acquiring community-associated ESBL infection include use of corticosteroids [66] and personal history of diabetes mellitus [66, 67], which is relevant for our study because, at $11.6 \%$, Romania is one of the countries with the highest prevalence of diabetes mellitus in Europe [68]. Person-toperson transmission of ESBL-producing Enterobacterales within households has been documented in Spain [69], the 


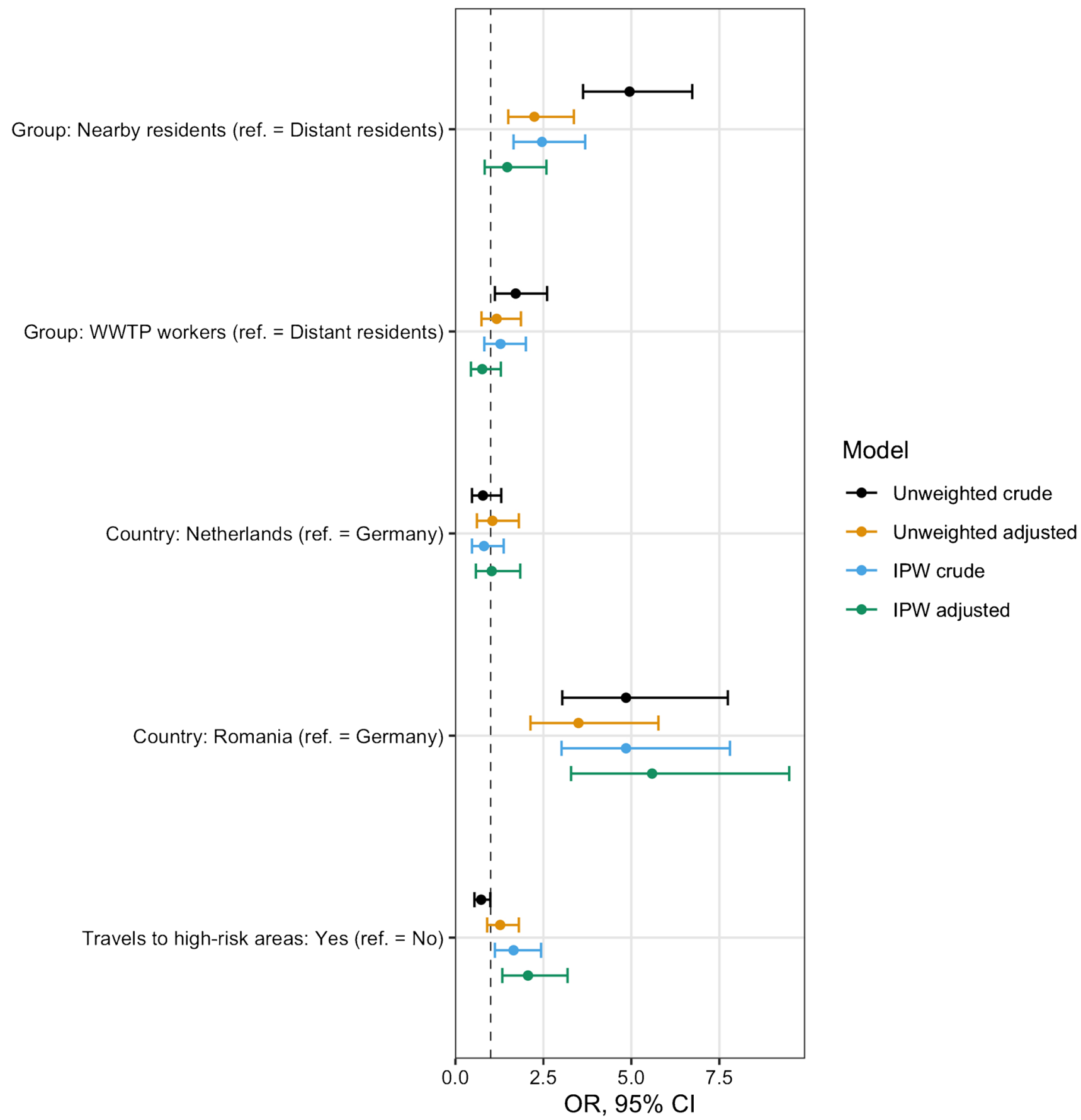

Fig. 3 Comparison of models estimating the effect of participation group (wastewater treatment plant-WWTP-worker, nearby resident, distant resident) as a proxy for exposure routes (ingestion of droplets, hand-to-mouth contact, or inhalation of aerosols) in and around the local WWTP on the presence of ESBL-producing E. coli in stool samples, AWARE Study, 2021. Models adjusted for age, sex, education, country, travels to high risk areas, working with human tissues, antibiotic use, farm visits, hospital visits as patient and hospital visits as a professional. IPW: Inverse Probability Weighted model. ref. $=$ Reference level. Travel to high risk areas for AR in the past year includes travels to North Africa, Sub-Saharan Africa, Asia, Central and South America, as well as the European countries Italy, Greece, Bulgaria, and Slovenia. Crude: Model with only the given variable, ignoring potential covariates. Adjusted: Model with the given variable, including all potential covariates in the exposureoutcome relation. Unweighted: Model without applying inverse probability weights (IPW). Weighted: Model applying inverse probability weights (IPW). See text for details 
Table 2 Unweighted models for the carriage of ESBL-producing E. coli, stratified by country, n=1940, AWARE Study, 2021

\begin{tabular}{|c|c|c|c|c|c|c|}
\hline & \multicolumn{2}{|l|}{ Germany, $n=482$} & \multicolumn{2}{|c|}{ The Netherlands, $\mathrm{n}=828$} & \multicolumn{2}{|l|}{ Romania, $\mathrm{n}=608$} \\
\hline & $\operatorname{cOR}(95 \% \mathrm{CI})^{\mathrm{a}}$ & $\mathrm{aOR}(95 \% \mathrm{CI})^{\mathrm{b}}$ & $\operatorname{cOR}(95 \% \mathrm{CI})^{\mathrm{a}}$ & $\mathrm{aOR}(95 \% \mathrm{CI})^{\mathrm{b}}$ & $\operatorname{cOR}(95 \% \mathrm{CI})^{\mathrm{a}}$ & $\mathrm{aOR}(95 \% \mathrm{CI})^{\mathrm{b}}$ \\
\hline Group: Nearby resident ${ }^{c}$ & $0.72(0.27-1.90)$ & $0.81(0.29-2.30)$ & d & d & $\begin{array}{l}3.73 \\
(2.18-6.38)\end{array}$ & $\begin{array}{l}3.17 \\
(1.80-5.59)\end{array}$ \\
\hline Group: WWTP worker & $\begin{array}{l}0.00 \\
(0-\operatorname{Inf})^{\mathrm{e}}\end{array}$ & $\begin{array}{l}0.00 \\
(0-\text { Inf })^{\mathrm{e}}\end{array}$ & $\begin{array}{l}0.71 \\
(0.31-1.62)\end{array}$ & $\begin{array}{l}0.95 \\
(0.37-2.44)\end{array}$ & $\begin{array}{l}2.01 \\
(1.08-3.74)\end{array}$ & $\begin{array}{l}2.34 \\
(1.22-4.50)\end{array}$ \\
\hline Educational level: $\operatorname{High}^{\mathrm{f}}$ & $1.72(0.71-4.17)$ & $1.16(0.45-2.99)$ & $\begin{array}{l}2.07 \\
(1.10-3.89)\end{array}$ & $\begin{array}{l}1.85 \\
(0.95-3.59)\end{array}$ & $\begin{array}{l}0.46 \\
(0.30-0.70)\end{array}$ & $\begin{array}{l}0.66 \\
(0.41-1.04)\end{array}$ \\
\hline Sex: Male & $0.92(0.42-1.98)$ & $1.01(0.45-2.24)$ & $\begin{array}{l}0.92 \\
(0.51-1.65)\end{array}$ & $\begin{array}{l}0.93 \\
(0.48-1.8)\end{array}$ & $\begin{array}{l}0.95 \\
(0.67-1.36)\end{array}$ & $\begin{array}{l}1.05 \\
(0.70-1.56)\end{array}$ \\
\hline Age & $0.97(0.95-1.01)$ & $0.98(0.95-1.01)$ & $\begin{array}{l}1.01 \\
(0.98-1.03)\end{array}$ & $\begin{array}{l}1.01 \\
(0.99-1.03)\end{array}$ & $\begin{array}{l}0.98 \\
(0.96-0.99)\end{array}$ & $\begin{array}{l}0.98 \\
(0.96-0.99)\end{array}$ \\
\hline Travels to high-risk areas: Yes $^{\mathrm{g}}$ & $2.41(0.99-5.90)$ & $2.29(0.90-5.78)$ & $\begin{array}{l}2.03 \\
(1.11-3.69)\end{array}$ & $\begin{array}{l}1.92 \\
(1.04-3.52)\end{array}$ & $\begin{array}{l}0.54 \\
(0.32-0.92)\end{array}$ & $\begin{array}{l}0.75 \\
(0.43-1.32)\end{array}$ \\
\hline $\begin{array}{l}\text { Work with patients or human tissues: } \\
\text { Yes }^{\text {h }}\end{array}$ & $0.88(0.38-2.06)$ & $0.99(0.40-2.43)$ & $\begin{array}{l}0.70 \\
(0.37-1.32)\end{array}$ & $\begin{array}{l}0.72 \\
(0.37-1.4)\end{array}$ & $\begin{array}{l}0.54 \\
(0.32-0.93)\end{array}$ & $\begin{array}{l}0.59 \\
(0.32-1.07)\end{array}$ \\
\hline Hospital visits as a patient: Yes & $0.97(0.34-2.79)$ & $1.00(0.33-2.99)$ & $\begin{array}{l}0.39 \\
(0.05-2.91)\end{array}$ & $\begin{array}{l}0.42 \\
(0.05-3.31)\end{array}$ & $\begin{array}{l}1.18 \\
(0.65-2.16)\end{array}$ & $\begin{array}{l}1.02 \\
(0.52-2.03)\end{array}$ \\
\hline Hospital visits as a professional: Yes & $0.48(0.06-3.63)$ & $0.44(0.05-3.50)$ & $\begin{array}{l}1.28 \\
(0.16-10.04)\end{array}$ & $\begin{array}{l}1.31 \\
(0.15-11.23)\end{array}$ & $\begin{array}{l}0.59 \\
(0.13-2.62)\end{array}$ & $\begin{array}{l}1.20 \\
(0.22-6.46)\end{array}$ \\
\hline Use of antibiotics: Yes & $1.19(0.52-2.72)$ & $1.09(0.46-2.55)$ & $\begin{array}{l}0.80 \\
(0.35-1.82)\end{array}$ & $\begin{array}{l}0.86 \\
(0.36-2.02)\end{array}$ & $\begin{array}{l}0.98 \\
(0.64-1.49)\end{array}$ & $\begin{array}{l}1.28 \\
(0.77-2.12)\end{array}$ \\
\hline Farm visits: Yes & $0.86(0.32-2.34)$ & $0.99(0.35-2.83)$ & $\begin{array}{l}1.13 \\
(0.43-2.95)\end{array}$ & $\begin{array}{l}1.34 \\
(0.5-3.56)\end{array}$ & $\begin{array}{l}0.00 \\
(0-\text { Inf })^{j}\end{array}$ & $\begin{array}{l}0.00 \\
(0-\text { Inf })^{\mathrm{j}}\end{array}$ \\
\hline
\end{tabular}

ESBL Extended-Spectrum Beta-Lactamases, AR Antibiotic Resistance

${ }^{\mathrm{a}} \mathrm{COR}$ : crude odds ratio

baOR: adjusted odds ratio

${ }^{\mathrm{c}}$ Nearby residents live within a $300 \mathrm{~m}$ radius from a WWTP

${ }^{\mathrm{d}}$ Data on Nearby residents in the Netherlands was not collected

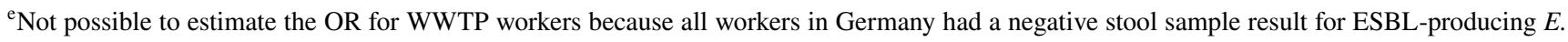
coli

${ }_{\mathrm{f}}^{\mathrm{f}}$ Educational level according to the International Standard Classification of Education (ISCED): Low = ISCED 0-2 (Pre-primary education to Lower secondary education), High $=\mathrm{ISCED} \geq 3$ (Upper secondary education to Doctoral or equivalent)

${ }^{\mathrm{g}}$ Travel to high risk areas for AR in the past year: Includes travels to North Africa, Sub-Saharan Africa, Asia, Central and South America, as well as the European countries Italy, Greece, Bulgaria and Slovenia

${ }^{\mathrm{h}}$ Work with patients or human tissues in the past year: Includes self-reported contact with patients at work and with human tissues (e.g. blood, urine, sputum, feces, vomit, saliva, or primary cell lines)

${ }^{\mathrm{j}}$ Not possible to estimate the OR for farm visits because all participants who stated visiting a farm in the past year had a negative stool sample result for ESBL-producing $E$. coli

Netherlands [70], and the USA [71], even showing identical strains between patients who had community-acquired infections with ESBL-producing Enterobacterales and their household members [72]. Additionally, ethnicity encodes cultural, social, and health behaviors that could result in a higher carriage rate for ESBL-EC [73]. From the door-todoor visits, differences in household size, sociodemographic characteristics, and underlying comorbidities were observed for nearby residents in Romania, although not systematically recorded. Therefore, these risk factors might differ between exposure groups in Romania at a greater degree than in the other countries.
Within the Romanian population, there is also a striking difference in travels to high-risk areas for AR depending on their participation group: although the proportion of participants among WWTP workers and the distant residents is similar regarding travels to high-risk areas for AR (30\% and $33 \%$ ), the proportion of nearby residents traveling to these high-risk areas for AR was, in comparison, low (10\%). We observed a similar trend regarding educational level, where the proportion of highly educated participants in Romania was higher for WWTP workers and distant residents (97\% and $91 \%)$ than for nearby residents (65\%). In fact, when considering country of residence as an interaction term 
for the effect of participation group on carriage of ESBLEC (Online Resource Table 4), the effect of Romania as country of residence alone disappeared (aOR 1.55, 95\% CI: 0.79-3.05), while the effect of being a nearby resident in Romania carried the observed effect (aOR 5.49, 95\% CI: 1.79-16.80). As frequency of travels and educational levels are proxies for socio-economic status (SES), we suspect that nearby residents in Romania have a lower SES, which would then affect our exposure-outcome relation. Although we did not directly collect data about SES, the constructed DAG (Fig. 2) confirmed that adjusting for other potential confounders is enough to find an unbiased estimate for the direct causal effect of proximity to WWTP (defined by participation group) on carriage of ESBL-EC. In our study, we did not measure the full extent of SES (only partially by e.g. education). Thus, SES is an unobserved confounder of the causal effect of participation group on carriage of ESBLEC. It was therefore not possible to calculate an unbiased total effect of the exposure-outcome relation. However, adjusting for age, sex, education, country, travels to high risk areas for AR, antibiotics use, farm visits, work with patients or tissues, hospital visits as patients, and hospital visits as a professional made it possible to estimate the direct causal effect.

\section{Strengths and limitations}

As far as we know, and despite the abundance of studies analyzing ARB in water and air samples from WWTPs [21-24], this is the first study investigating the carriage of ESBL-producing Enterobacterales in humans hypothesized to be exposed through ingestion of droplets, hand-to-mouth contact, or inhalation of aerosols due to close proximity to a WWTP, either from working at a WWTP or from living in the surroundings. Several characteristics make the AWARE Study unique in its design. Data collection was conducted in three European countries with different background prevalences for AR. We explored the exposure-outcome relation defining two exposed groups and one comparison group, we followed a systematic sampling of participants adapted to the local regulations and logistical capabilities, we used reminders and incentives to increase participation, we developed our study questionnaire within a multidisciplinary team of experts, we used validated questions whenever possible, we conducted a pilot study to assess the feasibility of our methods, we conducted quality control processes for data input and data cleaning processes, we used standardized operating procedures (SOPs) in all three locations to guarantee laboratory methods to be comparable, and used positive controls for culture analyses. Additionally, we avoided using data-driven methods for variable selection. Instead, we conducted a thoughtful identification of potential confounders a priori with the help of a directed acyclic graph, and we used methods such as multiple imputation and inverse probability of sampling weights to analytically reduce the impact of missing values and low response. Our results are consistent in sensitivity analyses using alternative analytical methods to model our exposure-outcome relation: Traditional unweighted logistic regression models with complete case analysis and imputed analysis (Online Resource Table 3), unweighted stratified models by country (Table 2), model using country of residence as an interaction term (Online Resource Table 4).

Our study is, however, not exempt of limitations. Threats to internal validity include the risk of selection bias evidenced by the low participation response, especially in Germany and the Netherlands, for which we decided to use inverse probability of sampling weights. In our study, we suspect that the reasons for the observed low response in WWTP workers, nearby, and distant residents from Germany (response $22 \%, 6.95 \%$, and $11 \%$ ) and in the Netherlands (response $26 \%$, and $6.4 \%$ ) when compared with the response in Romania (response 62\%, 53\%, and 54\%), reflect our recruitment methods and possibly background potential cultural differences among the countries. In Germany and in the Netherlands, we invited potential participants using invitation letters sent by postal service, whereas in Romania, we used a door-to-door approach because, in our experience, this method is more effective in Romania than postal letters. Also, studies involving stool samples have been reported to have a low response because of inherent reasons related to the nature of the stool sample $[74,75]$. These reasons put our study at risk of selection bias. Inverse probability of sampling weights has been described as an analytical method to adjust for selection bias where weights are assigned based on the factors that generate selection, which in our case is the response, and thus serve to reduce the differences between the study population and the target population $[51,76]$.

Additionally, after recruitment and applying exclusion criteria for the analysis, we failed to reach the desired sample size for nearby residents in Germany and in Romania. We also failed to reach the desired sample size for workers in Germany at the recruitment stage. This has implications for the statistical power of our study to detect a desired effect, if there is in fact one. A post hoc power test restricted to study participants who completed all study phases (including providing a stool sample) shows that our data provides us with $63 \%$ and $75 \%$ statistical power to detect a minimum OR of 1.7 in workers and in nearby residents, when compared with distant residents.

Further, our data showed a proportion of $8 \%$ of missing values on the ESBL-EC carriage across countries $(n=163)$. Some of these missing values came from samples collected in the Netherlands $(n=4)$ and in Romania $(n=45)$ but the majority of the missing values for stool samples came from Germany $(n=114)$. Our data collection methods in Germany 
shed some light into this large number of missing values: only participants who had already completed the baseline questionnaire received a stool sample kit, and then were given a short time frame to hand in stool samples in person at the previously arranged time and place. These constraints were caused by the limited availability of the local microbiological laboratory to process samples, by the fact that we could not guarantee adequate preservation of samples if sent to the laboratory by postal service, and thus having to collect stool samples in person. Consequently, these values are missing completely at random or, worst case scenario, missing at random conditional on the country of residence. We are confident that randomness is key in the missing mechanism because participants would not have been able to selfassess their AR carriage status a priori. Besides fulfilling the randomness assumption for applying multiple imputation in our data, we performed post hoc imputation diagnostics by comparing models with complete cases vs. after imputation and did not find major differences in the directionality of estimates (Online Resource Table 3).

Finally, we have not included information about the heterogeneity of treatment processes in WWTPs across the three countries, nor have we included specific working conditions at the WWTP for the workers. Actual contact with raw wastewater can be limited to occasional sampling but could pose a higher threat of exposure depending on the time spent at certain locations within the WWTP, the type of activity performed, and the frequency of given activity, which are relevant factors for exposure intensity. Upcoming analyses from our project will include a formal exposure assessment for these study populations based on spatial techniques including physical distance of participants to the WWTPs, working conditions and preventive behavior at work for WWTP workers, and the specific operative characteristics of enrolled WWTPs.

\section{Conclusions}

To the best of our knowledge, this is the first study investigating the carriage of ESBL-producing Enterobacterales in humans exposed to antibiotic resistant factors due to close proximity to a WWTP, either from working at a WWTP or from living in the surroundings. Using data collected in Germany, the Netherlands, and Romania, we did not find evidence of an increased risk of carriage of ESBL-producing E. coli in WWTP workers or in nearby residents across the three countries, as compared to the general population. We did find an increased risk for carriage of ESBL-EC in the subset of the Romanian population, both in WWTP workers and in nearby residents, which could be at least partially attributed to the local WWTP. However, this effect was higher for nearby residents than for workers, which suggests that, for nearby residents, unmeasured confounding factors could contribute to the increased carriage. Upcoming analyses from this project will perform exposure assessment using spatial techniques, including working conditions at WWTPs and working behavior from WWTP workers, and considering the heterogeneity of WWTP characteristics in terms of treatment efficacy and its consequences for the environment.

Supplementary Information The online version contains supplementary material available at https://doi.org/10.1007/s10096-021-04387-z.

Acknowledgements We would like to thank Dr. Jana Bader at the Max von Pettenkofer Institute of LMU Munich for their support and expertise regarding analyses in Germany. We would also like to thank Nicole Stasch, Pezi Mang, Kim Weiszhar, Sonja Strieker, Marieke Behlen, and Nicole Schäfer for their hard work and support during the field phase of the study. Additionally, we extend our gratitude to WWTP workers, operators, nearby and distant residents around WWTP for their support, collaboration, and assistance during the sampling campaign and data collection.

Author contribution Study conception and design: MCC, DGJL, KR, DN, AW, AMRH, HS. Fieldwork and data collection: DRM, HB, MB, MK, LM, GP, LW. Microbiology: HB, MB, MK, LM, GP, MCC, BS, AW, AMRH, HS. Data cleaning and analysis: DRM, HB, MB. Interpretation of the data: DRM, FB, HB, CFF, TW, LW, DGJL, KR, AMRH, HS. Drafting of the manuscript: DRM. All authors read and approved the final manuscript.

Funding Open Access funding enabled and organized by Projekt DEAL. AWARE (Antibiotic Resistance in Wastewater: Transmission Risks for Employees and Residents around Wastewater Treatment Plants) is supported by the European Commission (JPI-EC-AMR ERA-Net Cofund grant no 681055), the Bundesministerum für Bildung und Forschung, DLR Projektträger (01KI1708), UEFISCDI project ERANET-JPI-EC-AMR-AWARE-WWTP No. 26/2017, the Netherlands Organisation for Health Research and Development, The Hague, the Netherlands (ZonMw, grant 547001007, https://www.zonmw.nl/), and the Swedish Research Council VR Grant No. 2016-06512, all within the $5^{\text {th }}$ JPI AMR framework on transmission dynamics.

Availability of data and material Data and materials are available upon request.

Code availability Code is available upon request.

\section{Declarations}

Ethics approval and consent to participate This study was approved by the Ethics Committee of the University of Munich (LMU) (ProjectNo. 17-734) and by the Research Ethics Committee of the University of Bucharest (Registration-No. 164/05.12.2017). In the Netherlands, this research is exempted for ethical approval under the Dutch Medical Research Involving Human Subjects Act (WMO; Committee: Medisch Ethische Toetsingscommissie, number of confirmation: 19-001/C). All procedures performed in studies involving human participants were in accordance with the ethical standards of the institutional and national research committees and with the 1964 Helsinki declaration and its later amendments or comparable ethical standards, as well as with Directive 95/46/EC, and the 1977 Oviedo Convention of the Council of Europe on human rights and biomedicine. Written informed consent 
was obtained from all individual participants included in the study and their legal guardians when applicable.

Conflict of interest The authors declare no competing interests.

Open Access This article is licensed under a Creative Commons Attribution 4.0 International License, which permits use, sharing, adaptation, distribution and reproduction in any medium or format, as long as you give appropriate credit to the original author(s) and the source, provide a link to the Creative Commons licence, and indicate if changes were made. The images or other third party material in this article are included in the article's Creative Commons licence, unless indicated otherwise in a credit line to the material. If material is not included in the article's Creative Commons licence and your intended use is not permitted by statutory regulation or exceeds the permitted use, you will need to obtain permission directly from the copyright holder. To view a copy of this licence, visit http://creativecommons.org/licenses/by/4.0/.

\section{References}

1. European Centre for Disease Prevention and Control: surveillance of antimicrobial resistance in Europe 2018. Stockholm: ECDC; 2019 p. 110. Available from: https://doi.org/10.2900/22212

2. Polianciuc SI, Gurzău AE, Kiss B, Ştefan MG, Loghin F (2020) Antibiotics in the environment: causes and consequences. Med Pharm Rep 93:231-40. Available from: https://www.ncbi.nlm.nih. gov/pmc/articles/PMC7418837/. Accessed 31 May 2021

3. Bengtsson-Palme J, Larsson DGJ (2016) Concentrations of antibiotics predicted to select for resistant bacteria: proposed limits for environmental regulation. Environ Int 86:140-149

4. Finley RL, Collignon P, Larsson DGJ, McEwen SA, Li X-Z, Gaze WH et al (2013) The scourge of antibiotic resistance: the important role of the environment. Clin Infect Dis 57:704-710

5. Berendonk TU, Manaia CM, Merlin C, Fatta-Kassinos D, Cytryn E, Walsh F et al (2015) Tackling antibiotic resistance: the environmental framework. Nat Rev Microbiol 13:310-317

6. Martinez JL, Fajardo A, Garmendia L, Hernandez A, Linares JF, Martínez-Solano L et al (2009) A global view of antibiotic resistance. FEMS Microbiol Rev 33:44-65

7. Huijbers PMC, Blaak H, Jong MCM de, Graat EAM, Vandenbroucke-Grauls CMJE, Husman AM de R (2015) Role of the environment in the transmission of antimicrobial resistance to humans: a review. Available from: https://pubs.acs.org/doi/pdf/ 10.1021/acs.est.5b02566. Accessed 31 May 2021

8. Kraemer SA, Ramachandran A, Perron GG (2019) Antibiotic pollution in the environment: from microbial ecology to public policy. Microorganisms. 7:180. Available from: https://www. mdpi.com/2076-2607/7/6/180. Accessed 31 May 2021

9. Zhang S, Huang J, Zhao Z, Cao Y, Li B (2020) Hospital wastewater as a reservoir for antibiotic resistance genes: a meta-analysis. Front Public Health. 8:574968

10. Lépesová K, Olejníková P, Mackulak T, Cverenkárová K, Krahulcová M, Bírošová L (2020) Hospital wastewater-important source of multidrug resistant coliform bacteria with ESBL-production. Int J Environ Res Public Health 17

11. Leclercq R, Oberlé K, Galopin S, Cattoir V, Budzinski H, Petit F (2013) Changes in enterococcal populations and related antibiotic resistance along a medical center-wastewater treatment plant-river continuum. Appl Environ Microbiol 79:2428-2434

12. Bueno I, Williams-Nguyen J, Hwang H, Sargeant JM, Nault AJ, Singer RS (2018) Systematic review: impact of point sources on antibiotic-resistant bacteria in the natural environment. Zoonoses
Public Health 65:e162-84. Available from: http://onlinelibrary. wiley.com/doi/abs/10.1111/zph.12426. Accessed 31 May 2021

13. Bueno I, Williams-Nguyen J, Hwang H, Sargeant JM, Nault AJ, Singer RS (2017) Impact of point sources on antibiotic resistance genes in the natural environment: a systematic review of the evidence. Anim Health Res Rev 18:112-27. Available from: https:// www.cambridge.org/core/journals/animal-health-research-revie ws/article/impact-of-point-sources-on-antibiotic-resistance-genesin-the-natural-environment-a-systematic-review-of-the-evidence/ 9291877383591315C22B65608B373642. Accessed 31 May 2021

14. Pruden A, Larsson DGJ, Amézquita A, Collignon P, Brandt KK, Graham DW et al (2013) Management options for reducing the release of antibiotics and antibiotic resistance genes to the environment. Environ Health Perspect 121:878-885

15 Blaak H, van Hoek AHAM, Hamidjaja RA, van der Plaats RQJ, Kerkhof-de Heer L, de RodaHusman AM et al (2015) Distribution, numbers, and diversity of ESBL-producing E. Coli in the poultry farm environment. PloS One. 10:e0135402

16. Bréchet C, Plantin J, Sauget M, Thouverez M, Talon D, Cholley $P$ et al (2014) Wastewater treatment plants release large amounts of extended-spectrum $\beta$-lactamase-producing Escherichia coli into the environment. Clin Infect Dis 58:1658-1665

17. Brückner I, Kirchner K, Müller Y, Schiwy S, Klaer K, Dolny $R$ et al (2018) Status quo report on wastewater treatment plant, receiving water's biocoenosis and quality as basis for evaluation of large-scale ozonation process. Water Sci Technol 77:337-345

18. Yamashita N, Katakawa Y, Tanaka H (2017) Occurrence of antimicrobial resistance bacteria in the Yodo River basin, Japan and determination of beta-lactamases producing bacteria. Ecotoxicol Environ Saf 143:38-45

19. Zhang Q, Jia A, Wan Y, Liu H, Wang K, Peng H et al (2014) Occurrences of three classes of antibiotics in a natural river basin: association with antibiotic-resistant Escherichia coli. Environ Sci Technol 48:14317-14325

20. Sidrach-Cardona R, Hijosa-Valsero M, Marti E, Balcázar JL, Becares E (2014) Prevalence of antibiotic-resistant fecal bacteria in a river impacted by both an antibiotic production plant and urban treated discharges. Sci Total Environ 488-489:220-227

21 Bessa LJ, Barbosa-Vasconcelos A, Mendes A, Vaz-Pires P, Martins da Costa P (2014) High prevalence of multidrugresistant Escherichia coli and Enterococcus spp. In river water, upstream and downstream of a wastewater treatment plant. J Water Health. 12:426-35

22. Koczura R, Mokracka J, Jabłońska L, Gozdecka E, Kubek M, Kaznowski A (2012) Antimicrobial resistance of integron-harboring Escherichia coli isolates from clinical samples, wastewater treatment plant and river water. Sci Total Environ 414:680-685

23. Korzeniewska E, Korzeniewska A, Harnisz M (2013) Antibiotic resistant Escherichia coli in hospital and municipal sewage and their emission to the environment. Ecotoxicol Environ Saf 91:96-102

24. Korzeniewska E, Harnisz M (2013) Extended-spectrum betalactamase (ESBL)-positive Enterobacteriaceae in municipal sewage and their emission to the environment. J Environ Manage 128:904-911

25. Teixeira JV, Cecílio P, Gonçalves D, Vilar VJP, Pinto E, Ferreira HN (2016) Multidrug-resistant Enterobacteriaceae from indoor air of an urban wastewater treatment plant. Environ Monit Assess 188:388. Available from: https://doi.org/10.1007/s10661-016-5382-4

26. Flach C-F, Genheden M, Fick J, Joakim Larsson DG (2018) A comprehensive screening of Escherichia coli isolates from Scandinavia's largest sewage treatment plant indicates no selection for antibiotic resistance. Environ Sci Technol 52:11419-28. Available from: https://doi.org/10.1021/acs.est.8b03354

27. Bengtsson-Palme J, Hammarén R, Pal C, Östman M, Björlenius B, Flach C-F et al (2016) Elucidating selection processes for antibiotic resistance in sewage treatment plants using metagenomics. 
Sci Total Environ 572:697-712. Available from: https://www. sciencedirect.com/science/article/pii/S0048969716314176. Accessed 31 May 2021

28. Mao D, Yu S, Rysz M, Luo Y, Yang F, Li F et al (2015) Prevalence and proliferation of antibiotic resistance genes in two municipal wastewater treatment plants. Water Res 85:458-66. Available from: https://www.sciencedirect.com/science/article/pii/S0043 135415302220. Accessed 31 May 2021

29. Lu J, Tian Z, Yu J, Yang M, Zhang Y (2018) Distribution and abundance of antibiotic resistance genes in sand settling reservoirs and drinking water treatment plants across the Yellow River, China. Water 10:246. Available from: https://www.mdpi.com/ 2073-4441/10/3/246. Accessed 31 May 2021

30. Akiyama T, Asfahl KL, Savin MC (2010) Broad-host-range plasmids in treated wastewater effluent and receiving streams. J Environ Qual 39:2211-2215

31. Akiyama T, Savin MC (2010) Populations of antibiotic-resistant coliform bacteria change rapidly in a wastewater effluent dominated stream. Sci Total Environ 408:6192-6201

32. Conte D, Palmeiro JK, da Silva Nogueira K, de Lima TMR, Cardoso MA, Pontarolo R et al (2017) Characterization of CTX-M enzymes, quinolone resistance determinants, and antimicrobial residues from hospital sewage, wastewater treatment plant, and river water. Ecotoxicol Environ Saf 136:62-69

33. Zurfluh K, Bagutti C, Brodmann P, Alt M, Schulze J, Fanning $S$ et al (2017) Wastewater is a reservoir for clinically relevant carbapenemase- and 16s rRNA methylase-producing Enterobacteriaceae. Int J Antimicrob Agents 50:436-440

34. Osińska A, Korzeniewska E, Harnisz M, Niestępski S (2017) The prevalence and characterization of antibiotic-resistant and virulent Escherichia coli strains in the municipal wastewater system and their environmental fate. Sci Total Environ 577:367-375

35. Marti E, Huerta B, Rodríguez-Mozaz S, Barceló D, Jofre J, Balcázar JL (2014) Characterization of ciprofloxacin-resistant isolates from a wastewater treatment plant and its receiving river. Water Res 61:67-76

36. Yang F, Huang L, Li L, Yang Y, Mao D, Luo Y (2017) Discharge of KPC-2 genes from the WWTPs contributed to their enriched abundance in the receiving river. Sci Total Environ 581-582:136-143

37. Makowska N, Koczura R, Mokracka J (2016) Class 1 integrase, sulfonamide and tetracycline resistance genes in wastewater treatment plant and surface water. Chemosphere 144:1665-1673

38. Kotlarska E, Łuczkiewicz A, Pisowacka M, Burzyński A (2015) Antibiotic resistance and prevalence of class 1 and 2 integrons in Escherichia coli isolated from two wastewater treatment plants, and their receiving waters (Gulf of Gdansk, Baltic Sea, Poland). Environ Sci Pollut Res Int 22:2018-2030

39. Rizzo L, Manaia C, Merlin C, Schwartz T, Dagot C, Ploy MC et al (2013) Urban wastewater treatment plants as hotspots for antibiotic resistant bacteria and genes spread into the environment: a review. Sci Total Environ 447:345-360

40. Thorn J, Beijer L (2004) Work-related symptoms and inflammation among sewage plant operatives. Int J Occup Environ Health 10:84-89

41. Schöniger-Hekele M, Petermann D, Weber B, Müller C (2007) Tropheryma whipplei in the environment: survey of sewage plant influxes and sewage plant workers. Appl Environ Microbiol 73:2033-2035

42. Hooste WV, Charlier A-M, Rotsaert P, Bulterys S, Moens G, van Sprundel M et al (2010) Work-related Helicobacter pylori infection among sewage workers in municipal wastewater treatment plants in Belgium. Occup Environ Med 67:91-7. Available from: https://oem.bmj.com/content/67/2/91. Accessed 31 May 2021

43. Albatanony MA, El-Shafie MK (2011) Work-related health effects among wastewater treatment plants workers. Int J Occup Environ Med (The IJOEM) 2. Available from: https://www.theijoem.com/ ijoem/index.php/ijoem/article/view/104. Accessed 31 May 2021

44. Salviati C von, Laube H, Guerra B, Roesler U, Friese A (2015) Emission of ESBL/AmpC-producing Escherichia coli from pig fattening farms to surrounding areas. Vet Microbiol 175:77-84. Available from: https://www.sciencedirect.com/science/article/pii/ S0378113514004866. Accessed 31 May 2021

45. Wengenroth L, Berglund F, Blaak H, Chifiriuc MC, Flach C-F, Pircalabioru GG et al (2021) Antibiotic resistance in wastewater treatment plants and transmission risks for employees and residents: the concept of the AWARE study. Antibiotics 10:478. Available from: https://www.mdpi.com/2079-6382/10/5/478. Accessed 31 May 2021

46. ESRI 2011. ArcGIS Desktop: Release 10. Redlands, CA: Environmental Systems Research Institute.;

47. Luijkx R, de Heus M (2008) The educational system of the Netherlands. The international standard classification of education (ISCED97) An evaluation of content and criterion validity for. 15:47-75

48. BMBF TD des. ISCED 2011 - BMBF Datenportal. Datenportal des Bundesministeriums für Bildung und Forschung - BMBF. Available from: https://www.datenportal.bmbf.de/portal/de/gloss ary.html. Accessed 31 May 2021

49. Clasificarea Internațională Standard a Educației - ISCED (2018) Available from: https://www.parintiicerschimbare.ro/clasificareainternationala-standard-a-educatiei/. Accessed 31 May 2021

50. White IR, Royston P, Wood AM (2011) Multiple imputation using chained equations: issues and guidance for practice. Stat Med 30:377-99. Available from: https://onlinelibrary.wiley.com/doi/ abs/10.1002/sim.4067. Accessed 31 May 2021

51. Cole SR, Stuart EA (2010) Generalizing evidence from randomized clinical trials to target populations: the ACTG 320 trial. Am J Epidemiol 172:107-15. Available from: https://doi.org/10.1093/aje/kwq084

52. Pearl J (1995) Causal diagrams for empirical research. Biometrika 82:669-88. Available from: https://academic.oup.com/biomet/ article/82/4/669/251647. Accessed 31 May 2021

53. Greenland S, Pearl J, Robins JM (1999) Causal diagrams for epidemiologic research. Epidemiology 10:37-48. Available from: http://www.jstor.org/stable/3702180. Accessed 31 May 2021

54. R Core Team (2018) R: a language and environment for statistical computing. Vienna, Austria: R Foundation for Statistical Computing. Available from: https://www.R-project.org/. Accessed 31 May 2021

55. Nunes MS with contributions from T, Heuer C, Marshall J, Sanchez J, Thornton R, Reiczigel J et al (2018) epiR: Tools for the Analysis of Epidemiological Data. Available from: https:// CRAN.R-project.org/package=epiR. Accessed 31 May 2021

56. Buuren S van, Groothuis-Oudshoorn K (2011) Mice: multivariate imputation by chained equations in R. J Stat Softw 045. Available from: https://econpapers.repec.org/article/jssjstsof/v_3a045_ 3ai03.htm. Accessed 31 May 2021

57. Grund S, Robitzsch A, Luedtke O (2019) Mitml: Tools for Multiple Imputation in Multilevel Modeling. Available from: https:// CRAN.R-project.org/package $=$ mitml. Accessed 31 May 2021

58. Lumley T (2019) Mitools: Tools for Multiple Imputation of Missing Data. Available from: https://CRAN.R-project.org/package= mitools. Accessed 31 May 2021

59. Lumley T (2004) Analysis of complex survey samples. J Stat Softw 9:1-9. Available from: https://www.jstatsoft.org/index. php/jss/article/view/v009i08. Accessed 31 May 2021

60. Lumley T (2011) Complex Surveys: A Guide to Analysis Using R. John Wiley \& Sons

61. Östholm-Balkhed Å, Tärnberg M, Nilsson M, Nilsson LE, Hanberger H, Hällgren A et al (2013) Travel-associated faecal colonization with ESBL-producing Enterobacteriaceae: incidence and risk factors. J Antimicrob Chemother 68:2144-53. Available from: https://doi.org/10.1093/jac/dkt167

62. Tängdén T, Cars O, Melhus $\AA$, Löwdin E (2010) Foreign travel is a major risk factor for colonization with Escherichia coli producing CTX-M-type extended-spectrum $\beta$-Lactamases: a prospective study with Swedish volunteers. Antimicrob Agents Chemother 54:3564-8. Available from: https://aac.asm.org/content/54/9/ 3564. Accessed 31 May 2021 
63. Woerther P-L, Andremont A, Kantele A (2017) Travel-acquired ESBL-producing Enterobacteriaceae: impact of colonization at individual and community level. J Travel Med 24:S29-34. Available from: https://academic.oup.com/jtm/article/24/suppl_1/S29/ 3782737. Accessed 31 May 2021

64. Bengtsson-Palme J, Angelin M, Huss M, Kjellqvist S, Kristiansson E, Palmgren $\mathrm{H}$ et al (2015) The human gut microbiome as a transporter of antibiotic resistance genes between continents. Antimicrob Agents Chemother 59:6551-6560

65. Paltansing S, Vlot JA, Kraakman MEM, Mesman R, Bruijning ML, Bernards AT et al (2013) Extended-spectrum $\beta$-lactamaseproducing enterobacteriaceae among travelers from the Netherlands. Emerg Infect Dis 19:1206-1213

66. Castillo-Tokumori F, Irey-Salgado C, Málaga G (2017) Worrisome high frequency of extended-spectrum beta-lactamase-producing Escherichia coli in community-acquired urinary tract infections: a case-control study. Int J Infect Dis 55:16-9. Available from: https://linkinghub.elsevier.com/retrieve/pii/S1201971216316502. Accessed 31 May 2021

67. Dhillon RH-P, Clark J (2011) ESBLs: a clear and present danger? Crit Care Res Pract 2012:e625170. Available from: https://www. hindawi.com/journals/ccrp/2012/625170/. Accessed 31 May 2021

68. Mota M, Popa SG, Mota E, Mitrea A, Catrinoiu D, Cheta DM et al (2016) Prevalence of diabetes mellitus and prediabetes in the adult Romanian population: PREDATORR study. J Diabetes 8:336-344

69. Valverde A, Grill F, Coque TM, Pintado V, Baquero F, Cantón R et al (2008) High rate of intestinal colonization with extendedspectrum- $\beta$-lactamase-producing organisms in household contacts of infected community patients. J Clin Microbiol 46:2796-9. Available from: https://www.ncbi.nlm.nih.gov/pmc/articles/ PMC2519510/. Accessed 31 May 2021

70. Haverkate MR, Platteel TN, Fluit AC, Cohen Stuart JW, Leverstein-van Hall MA, Thijsen SFT et al (2017) Quantifying within-household transmission of extended-spectrum $\beta$-lactamaseproducing bacteria. Clin Microbiol Infect 23(46):e1-7

71. Madigan T, Johnson JR, Clabots C, Johnston BD, Porter SB, Slater BS et al (2015) Extensive household outbreak of urinary tract infection and intestinal colonization due to extended-spectrum $\beta$-lactamase-producing Escherichia coli sequence type 131. Clin Infect Dis 61:e5-12

72. Doi Y, Iovleva A, Bonomo RA (2017) The ecology of extendedspectrum $\beta$-lactamases (ESBLs) in the developed world. J Travel Med 24:S44-51. Available from: https://www.ncbi.nlm.nih.gov/ pmc/articles/PMC5731446/. Accessed 31 May 2021

73. Wickramasinghe NH, Xu L, Eustace A, Shabir S, Saluja T, Hawkey PM (2012) High community faecal carriage rates of CTX-M ESBL-producing Escherichia coli in a specific population group in Birmingham, UK. J Antimicrob Chemother 67:1108-13. Available from: https://doi.org/10.1093/jac/dks018

74. Lecky DM, Nakiboneka-Ssenabulya D, Nichols T, Hawkey P, Turner K, Chung K-T et al (2017) Informing future research for carriage of multiresistant Gram-negative bacteria: problems with recruiting to an English stool sample community prevalence study. BMJ Open 7:e017947. Available from: https://bmjopen.bmj.com/ content/7/12/e017947. Accessed 31 May 2021

75. Feigelson HS, Bischoff K, Ardini M-AE, Ravel J, Gail MH, Flores $R$ et al (2014) Feasibility of self-collection of fecal specimens by randomly sampled women for health-related studies of the gut microbiome. BMC Res Notes 7:204. Available from: https://doi. org/10.1186/1756-0500-7-204

76. Haneuse S, Schildcrout J, Crane P, Sonnen J, Breitner J, Larson E (2009) Adjustment for selection bias in observational studies with application to the analysis of autopsy data. Neuroepidemiology 32:229-239

Publisher's note Springer Nature remains neutral with regard to jurisdictional claims in published maps and institutional affiliations.

\section{Authors and Affiliations}

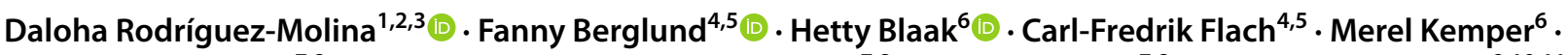

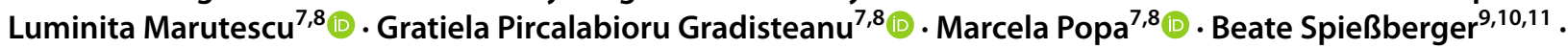 Tobias Weinmann $^{1}$ - Laura Wengenroth ${ }^{1}$ - Mariana Carmen Chifiriuc ${ }^{7,8}$ (1) D. G. Joakim Larsson ${ }^{4,5}$ (D)

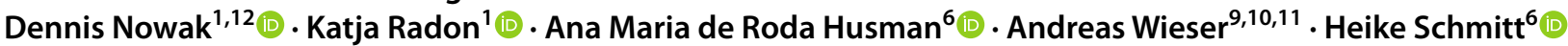

1 Occupational and Environmental Epidemiology and NetTeaching Unit, Institute and Clinic for Occupational, Social and Environmental Medicine, University Hospital, LMU Munich, Ziemssenstr. 5, 80336 Munich, Germany

2 Institute for Medical Information Processing, Biometry, and Epidemiology - IBE, LMU Munich, Munich, Germany

3 Pettenkofer School of Public Health, Munich, Germany

4 Department of Infectious Diseases, Institute of Biomedicine, The Sahlgrenska Academy, University of Gothenburg, Gothenburg, Sweden

5 Centre for Antibiotic Resistance Research (CARe), University of Gothenburg, Gothenburg, Sweden

6 Centre of Infectious Disease Control, National Institute for Public Health and the Environment, Bilthoven, The Netherlands
7 Department of Microbiology and Immunology, Faculty of Biology, University of Bucharest and the Academy of Romanian Scientists, Bucharest, Romania

8 Earth, Environmental and Life Sciences Section, Research Institute of the University of Bucharest, University of Bucharest, Bucharest, Romania

9 German Centre for Infection Research (DZIF) Partner Site Munich, Munich, Germany

10 Max Von Pettenkofer Institute, Faculty of Medicine, LMU Munich, Munich, Germany

11 Department of Infectious Diseases and Tropical Medicine, LMU University Hospital Munich, Munich, Germany

12 German Center for Lung Research (DZL), Comprehensive Pneumology Center Munich (CPC-M), Munich, Germany 